\title{
Post-facelift flap necrosis treatment using charged polystyrene microspheres
}

\author{
Oren Weissman $\mathrm{MD}^{1 *}$, Nimrod Farber $\mathrm{MD}^{1 *}$, Eric Remer $\mathrm{MD}^{1}$, Ariel Tessone MD${ }^{1}$, Omer Trivizki BMedSc${ }^{2}$,
} Jonathan Bank $M D^{3}$, Eyal Winkler $M D^{1}$, Isaac Zilinsky $M^{1,4}$, Josef Haik MD MPH${ }^{1}$

\begin{abstract}
O Weissman, N Farber, E Remer, et al. Post-facelift flap necrosis treatment using charged polystyrene microspheres. Can J Plast Surg 2013;21(1):45-47.
\end{abstract}

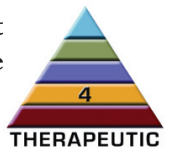

BACKGROUND: Flap necrosis following facial rhytidectomy constitutes a vexing and grievous complication to the patient and the surgeon. Treatment modalities that can expedite wound healing and re-epithelialization rates are highly desired.

OBJECTIVES: To assess wound healing and re-epithelialization rates of open wounds following postrhytidectomy flap necrosis treated with commercially available charged polystyrene microspheres (Polyheal-1, Polyheal Ltd, Israel).

METHODS: Flap necrosis following rhytidectomy with open wounds in three female patients were treated using dressings soaked with Polyheal-1. Wound closure rates were documented.

RESULTS: The wounds demonstrated both accelerated granulation tissue formation and rapid re-epithelialization rates. No complications or side effects were encountered.

CONCLUSIONS: Charged polystyrene microspheres may offer a new and efficacious way to treat open wounds due to flap necrosis following facial rhytidectomy. Further research with larger patient numbers is still needed to verify these findings.

Key Words: Charged polystyrene microspheres; Face-lift complications; Flap necrosis; Open wound

C ervicofacial rhytidectomy procedures have become a mainstay for plastic surgeons during the past 20 years. Evolution in surgical techniques have led to more natural repositioning of facial elements, thus providing long-lasting results. This, in turn, has raised public interest and demand for the procedure. According to the American Society of Plastic Surgeons, in 2011, 119,026 facelift procedures were performed in the United States alone (1).

However, facelifts still entail healing periods that sometimes span weeks and can be aggravated by complications. Common complications include postoperative hematoma, flap necrosis, seroma formation, motor and sensory nerve injury, alopecia, auricular deformity or displacement, and dyspigmentation (2-6). Of these, hematoma remains the most common complication and can lead to prolonged facial edema and, eventually, flap necrosis (3).

Flap necrosis itself constitutes a vexing and grievous complication for both the patient and the surgeon, with a reported incidence rate of $0 \%$ to $3 \%$ (1). In these instances, usually after sloughing of the necrotic flap edge, an open preauricular and/or postauricular wound remains. The existing literature regarding the management of flap necrosis includes healing by secondary intention, surgical debridement, local administration of antibiotic preparations, moist dressings, vitamin injections and hydrofibre dressings (7-9).

Recently, a new commercially available suspension, Polyheal-1 (Polyheal Ltd, Israel), has been introduced to the market aiming to
Le traitement de la nécrose d'un lambeau après une rhytidectomie du visage au moyen de microsphères chargées de polystyrène

HISTORIQUE : La nécrose d'un lambeau après une rhytidectomie du visage est une complication délicate et pénible pour le patient et le chirurgien. Des modalités thérapeutiques qui peuvent accélérer le taux de guérison et de réépithélialisation de la plaie sont fort souhaitables.

OBJECTIFS : Évaluer le taux de guérison et de réépithélialisation de plaies ouvertes après la nécrose d'un lambeau de rhytidectomie traité à l'aide de microsphères chargées de polystyrène commerciales (Polyheal-1, Polyheal Ltd, Israël).

MÉTHODOLOGIE : Les médecins ont traité la nécrose d'un lambeau après une rhytidectomie comportant des plaies ouvertes chez trois patientes à l'aide de pansements imbibés de Polyheal-1. Ils ont consigné le taux de fermeture des plaies.

RÉSULTATS : Les plaies ont présenté à la fois la formation accélérée de tissu de granulation et un taux de réépithélialisation rapide. Cette guérison ne s'est pas accompagnée de complications, ni d'effets secondaires.

CONCLUSIONS : Les microsphères chargées de polystyrène offrent peut-être un moyen nouveau et efficace de traiter des plaies ouvertes causées par la nécrose d'un lambeau après une rhytidectomie du visage. Des recherches plus approfondies auprès d'un plus grand nombre de patients s'imposent pour confirmer ces observations.

expedite wound healing. Polyheal-1 is a water-based, sterile $0.025 \%$ suspension of charged polystyrene $5-\mu \mathrm{m}$ microspheres (CPM) in a nutritional medium. There is evidence to suggest that the size and surface properties of the CPM contribute to the provision of a supportive, healing microenvironment on the wound surface by serving as an additional surface for the attachment and migration of epithelial, endothelial and inflammatory cells $(10,11)$. Negatively charged microspheres have been shown to induce a pulmonary inflammatory process in rabbits through enhanced release of inflammatory mediators such as substance P and histamine (12). It is proposed that CPM activate different cell populations in the wound bed (ie, inflammatory cells, fibroblasts and keratinocytes) and, consequrntly, promote the growth of granulation tissue and remodelling of damaged skin tissue.

The objective of the present study was to assess wound healing and re-epithelialization rates of open wounds following postrhytidectomy flap necrosis treated with Polyheal-1.

\section{METHODS}

Patients who presented to the Department of Plastic and Reconstructive Surgery, Sackler School of Medicine, Tel Aviv University, Tel-Aviv, Israel, with flap necrosis following rhytidectomy (facelift or minifacelift procedures) and subsequent open wounds were included in the present study. If necessary, the wounds were debrided until a clean wound bed was achieved and followed by treatment with Polyheal-1.

\footnotetext{
*Authors who contributed equally

${ }^{1}$ Department of Plastic and Reconstructive Surgery, Sheba Medical Center, Tel Hashomer, Affiliated to Sackler School of Medicine; ${ }^{2}$ Sackler

Faculty of Medicine, Tel Aviv University, Tel Aviv, Israel; ${ }^{3}$ Section of Plastic and Reconstructive Surgery, Department of Surgery, University

of Chicago Medical Center, Chicago, Illinois, USA; ${ }^{4} \mathrm{MOHS}$ Unit, Sheba Medical Center, Tel Hashomer, Affiliated to Sackler School of

Medicine, Tel Aviv University, Tel-Aviv, Israel.

Correspondence: Dr Oren Weissman, 2 Bodenheimer Street, Tel-Aviv, Israel. Telephone 97-254-453-5066, 97-23-695-4353,

fax 97-23-530-2248, e-mail Orenweissman@gmail.com
} 
TABLE 1

Patient and wound characteristics, and treatment duration and sequelae

\begin{tabular}{|c|c|c|c|c|c|c|c|c|}
\hline \multirow[b]{2}{*}{ Patient } & \multirow{2}{*}{$\begin{array}{l}\text { Age, } \\
\text { years }\end{array}$} & \multirow{2}{*}{$\begin{array}{l}\text { Open wound } \\
\text { duration, days }\end{array}$} & \multicolumn{2}{|c|}{ Wound ${ }^{* \dagger}$ dimensions } & \multirow{2}{*}{$\begin{array}{c}\text { Treatment } \\
\text { duration, } \\
\text { days }\end{array}$} & \multirow{2}{*}{$\begin{array}{l}\text { Follow-up } \\
\text { period, } \\
\text { months }\end{array}$} & \multirow{2}{*}{$\begin{array}{l}\text { Resultant } \\
\text { scar }\end{array}$} & \multirow[b]{2}{*}{ Remarks } \\
\hline & & & Before treatment & After treatment & & & & \\
\hline 1 & 30 & 19 & $\begin{array}{l}9 \mathrm{~cm} \times 1.6 \mathrm{~cm}^{\star} \\
7 \mathrm{~cm} \times 1.4 \mathrm{~cm}^{\dagger}\end{array}$ & $\begin{array}{l}7.5 \mathrm{~cm} \times 0.5 \mathrm{~cm}^{\star} \\
5 \mathrm{~cm} \times 0.7 \mathrm{~cm}^{\dagger}\end{array}$ & 10 & 26 & $\begin{array}{l}\text { Nondepressed, } \\
\text { slightly } \\
\text { hypertrophic }\end{array}$ & $\begin{array}{l}\text { After numerous laser } \\
\text { treatments to cheek due } \\
\text { to hemangioma and } \\
\text { subsequent scarring }\end{array}$ \\
\hline 2 & 62 & 27 & $3.2 \mathrm{~cm} \times 1.2 \mathrm{~cm}^{*}$ & $2.3 \mathrm{~cm} \times 0.6 \mathrm{~cm}^{*}$ & 10 & 26 & $\begin{array}{l}\text { Nondepressed, } \\
\text { hypertrophic }\end{array}$ & None \\
\hline 3 & 46 & 30 & $\begin{array}{l}3 \mathrm{~cm} \times 1.5 \mathrm{~cm}(\text { right)* } \\
2.8 \mathrm{~cm} \times 1.3 \mathrm{~cm}(\text { left })^{\star}\end{array}$ & $\begin{array}{l}2.4 \mathrm{~cm} \times 0.6 \mathrm{~cm}(\text { right })^{*} \\
2.2 \mathrm{~cm} \times 0.4 \mathrm{~cm}(\text { left })^{\star}\end{array}$ & 11 & 14 & $\begin{array}{l}\text { Nondepressed, } \\
\text { slightly } \\
\text { hypertrophic }\end{array}$ & $\begin{array}{l}\text { Long-term steroid usage } \\
\text { due to asthma with } \\
\text { subsequent diabetes } \\
\text { mellitus }\end{array}$ \\
\hline
\end{tabular}

*Preauricular; ${ }^{\dagger}$ Postauricular

Daily dressing was performed in accordance with the manufacturer's instructions. Polyheal-1 suspension was directly applied over the clean, open wounds once per day, then covered with a sterile gauze that was soaked with the suspension. Dressings were left in place for $12 \mathrm{~h}$, after which the remaining suspension in the bottle $(15 \mathrm{~mL})$ was applied over the same gauze without change. Wounds were evaluated and documented via digital photography daily. Wound closure rates were measured manually and any adverse reactions (ie, local infection or allergic response) were documented. Treatment with Polyheal-1 was discontinued after adequate clinical improvement was noticed and the depressed wound bed had reached the level of the adjacent wound edges. Treatment was then continued with twice-daily application of ointment (Threolone [chloramphenicol 3.0\% and prednisolone $0.5 \%$ ], Abic Ltd, Israel) to inhibit the formation of hypergranulation until complete wound closure was achieved. Following wound closure, follow-up continued in the outpatient clinic.

\section{RESULTS}

Between 2010 and 2011, three female patients 30 to 62 years of age (mean age 46 years) presented to the department with flap necrosis following rhytidectomy and subsequent open wounds (Table 1). Patient 1 underwent a unilateral facelift in addition to removal of a subcutaneous lipoma from her cheek. She suffered from severely scarred skin due to multiple flash-pump dye laser treatments for an arteriovenous malformation in her cheek during childhood. Patient 2 underwent a facelift procedure with subsequent flap necrosis that was initially conservatively treated with hydrofibre dressings. Patient 3 received long-term oral steroids due to resistant asthma with subsequent diabetes mellitus. She underwent bilateral facelift and a revision of mastoplexy augmentation, and presented with wound dehiscence in both breasts and postauricular suture lines. To mitigate the negative effect of the oral steroid regimen, the patient was advised to take vitamin A supplements. Average wound duration before Polyheal-1 therapy was 25.3 days (range 19 to 30 days). The mean duration of Polyheal-1 treatment was 10.3 days (range 10 to 11 days). There were no documented adverse reactions, wound infection or allergic reactions during the treatment period. Patients did not report pain in the wound area or during dressing changes. During the Polyheal-1 treatment, the wound beds demonstrated accelerated formation of granulation tissue, with subsequent filling of the depressed wounds. Surprisingly, visibly accelerated reepithelialization rates were also noted. Wound dimensions decreased to a mean of $11.2 \mathrm{~mm}$ in height and $8.4 \mathrm{~mm}$ in width during the treatment period. In all patients, the treatment was discontinued when the granulation tissue had reached (and slightly exceeded) the level of the adjacent wound edges (Figures 1 and 2). All three patients noted improvement and rapid wound closure during the Polyheal-1 treatment and expressed their satisfaction. All three patients subsequently experienced slightly hypertrophic scarring and one patient (patient 1) required intralesional steroid therapy. The mean follow-up period was 22 months (range 14 to 26 months).

\section{DISCUSSION}

Flap necrosis after a facelift procedure represents a serious complication for both patient and surgeon. The patient has invested time and money, expecting facial rejuvenation and, instead, must deal with an open wound that can take weeks - or even months - to heal, with the prospect of unsightly scarring. A treatment modality that can precipitate wound healing, both in terms of filling the depressed wound as well as expediting re-epithelialization, is paramount. There are several options for the treatment of small areas of flap necrosis, which usually resolve uneventfully. However, larger areas of skin necrosis on the face and cheek can lead to unacceptable cosmetic deformities (2). Flap necrosis usually results from vascular compromise in the forms of decreased arterial perfusion, venous congestion or small vessel disease as observed in diabetes mellitus patients and chronic smokers. Other causes include late evacuation of hematoma and wide undermining of the skin flaps with wound closure under tension (2). Smoking is a major risk factor for skin sloughing because it has a negative effect on wound healing and flap vascularity. It is reported that the risk of sloughing is 12 -fold greater in smokers compared with nonsmokers $(13,14)$.

Unfortunately, the current literature on the management of flap necrosis is limited at best and treatment options are scant. Healing by secondary intention is primarily suitable for small areas of necrosis along the flap edge. These occur most commonly in the postauricular region and generally heal without complication. Other reported modalities include application of specific antibiotic preparations, moist wound dressings, regular wound cleansing with hydrogen peroxide, betadine soaks and surgical debridement (7). There have also been reports of local injections of vitamins (vitamins $\mathrm{A}, \mathrm{C}$ and $\mathrm{E}$ ) for the treatment of tissue necrosis (8). Other options for the management of acute open wounds include silver-containing hydrofibre/alginate dressing, such as Aquacel Ag (ConvaTec, USA), which was found to be superior to betadine for open surgical wound care (9). Apart from the options described herein, the existing literature on the management of flap necrosis after rhytidectomy is exiguous.

In an attempt to expedite secondary healing of these wounds, Polyheal-1 was suggested as a treatment option. A recent published study demonstrated the efficacy of Polyheal-1 in promoting granulation tissue formation in difficult-to-heal chronic wounds (mean wound age 153 weeks) of mixed etiologies including venous insufficiency ulcers, diabetic ulcers and post-traumatic wounds, either superficial or deep, with exposed tendons, bones and ligaments (15). As demonstrated in the study, Polyheal-1 clinically promoted the formation of granulation tissue in stagnant wounds that had a long history of failed previous treatments (ranging from four weeks up to several years). Recent unpublished observations suggest that the interaction of Polyheal-1 with inflammatory cells may promote accelerated wound healing by the stimulation of appropriate secretion of inflammatory cytokines and growth factors, and by affecting NADPH oxidasemediated redox signalling, which is a unique intracellular amplifier of diverse signalling pathways involved in tissue repair. All of these 

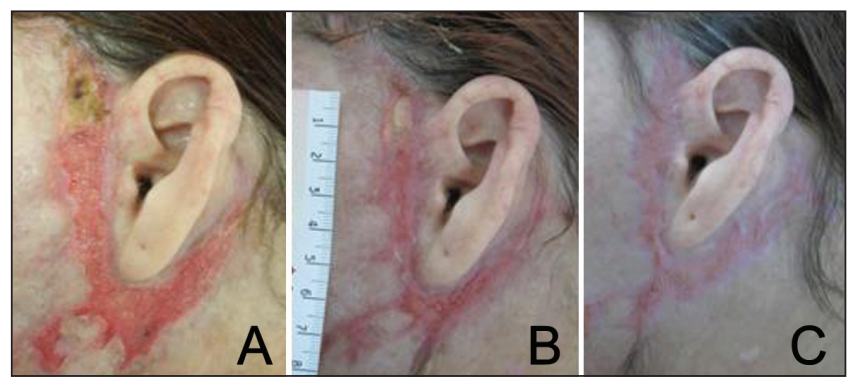

Figure 1) Patient 1 before (A) and at day 10 (B) after treatment with charged polystyrene microspheres (Polyheal-1, Polyheal Ltd, Israel). C Resulting scars two months later

factors may orchestrate the cell movements and granulation tissue formation necessary for repair.

In the current report, we present three patients with flap necrosis following a facelift procedure that was successfully treated with Polyheal-1 in our department. The application of Polyheal-1 is simple, safe and painless, thus rendering it a very appealing treatment option. The treatment was well tolerated. We demonstrated marked promotion of granulation tissue formation in wound beds with Polyheal-1 treatment. Surprisingly, we also witnessed expedited re-epithelization rates. The promotion of granulation tissue formation in the wound beds aided in filling the depressed wounds and in levelling of the scar formation plane with the adjacent wound edges. The fact that these effects were visible, coupled with daily improvement that was witnessed by both physicians and patients, aided in the psychological management of these patients. The resulting scars, although in both cases became progressively smaller due to scar contracture, remained a visible remnant of the complication.

\section{REFERENCES}

1. American Society of Plastic Surgeons. 2011 Plastic Surgery Procedural Statistics. <www.plasticsurgery.org/News-andResources/2011-Statistics-.html (Accessed July 25, 2012).

2. Griffin JE, Jo C. Complications after superficial plane cervicofacial rhytidectomy: A retrospective analysis of 178 consecutive facelifts and review of the literature. J Oral Maxillofac Surg 2007;65:2227-34.

3. Jones BM, Grover R. Avoiding hematoma in cervicofacial rhytidectomy: A personal 8-year old quest. Reviewing 910 patients. Plast Reconstr Surg 2004;113:381-7.

4. Brink RR. Auricular displacement with rhytidectomy. Plast Reconstr Surg 2002;109:408-9.

5. Daane SP, Owsley JQ. Incidence of cervical branch injury with "marginal mandibular nerve pseudo paralysis" in patients undergoing face lift. Plast Reconstr Surg 2003;111:2414-8.

6. Newman JP, Koch RJ, Goode RL, Brennan HG. Distortion of the auriculocephalic angle following rhytidectomy. Recognition and prevention. Arch Otolaryngol Head Neck Surg 1997;123:818-20.

7. Araco A, Gravante G, Araco F, Delogu D, Cervelli V.

Conservative management of flap necrosis after expanding hematoma for face lifting surgery. Dermatol Surg 2006;32:878-9; author reply 879-80.

8. Personelle J, Bolivar de Souza Pinto E, Ruiz RO. Injection of vitamin $\mathrm{A}$ acid, vitamin $\mathrm{E}$, and vitamin $\mathrm{C}$ for treatment of tissue necrosis. Aesthetic Plast Surg 1998;22:58-64.

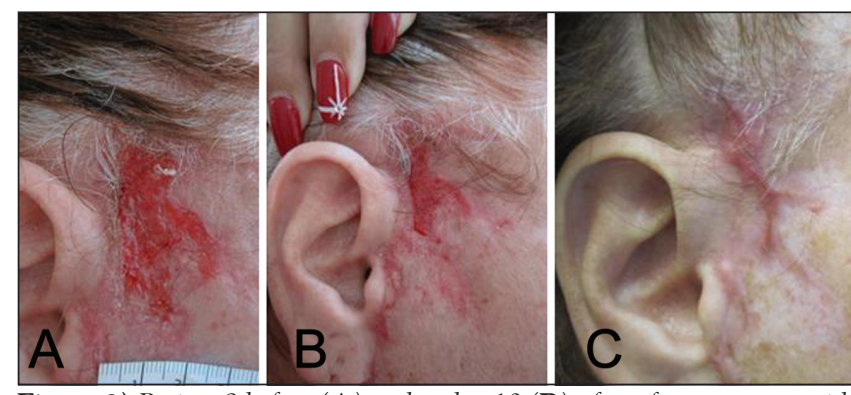

Figure 2) Patient 2 before (A) and at day 10 (B) after after treatment with charged polystyrene microspheres (Polyheal-1, Polyheal Ltd, Israel). C Resulting scars four months later

The treatment with Polyheal-1 did not, in our experience, help in achieving cosmetically appealing scars, even though it prevented the development of depressed scars. Some of these scars may require further management in the future.

Although preliminary, these findings suggest that Polyheal-1 could play a significant role in the future management of postoperative open wounds and, more specifically, in open wounds following flap failure on the face. However, the mechanism and impact of Polyheal-1 on open wounds should be confirmed and further elaborated by larger randomized controlled studies. It should be noted that several other studies are being conducted in our department examining the use of Polyheal-1 in other types of postoperative wounds and are yielding encouraging results.

DISCLOSURES: The authors have no financial disclosures or conflicts of interest to declare.

9. Jurczak F, Dugre T, Johnstone A, Offori T, Vujovic Z, Hollander D. Randomised clinical trial of hydrofiber dressing with silver versus povidone-iodine gauze in the management of open surgical and traumatic wounds. Int Wound J 2007;4:66-76.

10. Wu L, Mockros NE, Casperson ME, et al. Effects of electrically charged particles in enhancement of rat wound healing. J Surg Res 1999;85:43-50.

11. Sasaki A, Mueller RV, Xi G, Sipe R, Buck D, Hollinger J. Mast cells: An unexpected finding in the modulation of cutaneous wound repair by charged beads. Plast Reconstr Surg 2003;111:1446-53.

12. Nemmar A, Delaunois A, Nemery B, et al. Inflammatory effect of intratracheal instillation of ultrafine particles in the rabbit: Role of C-fiber and mast cells. Toxicol Appl Pharmacol 1999;160:250-61.

13. Rees TD, Liverett DM, Guy CL. The effect of cigarette smoking on skin flap survival in the facelift patient. Plast Reconstr Surg 1984;73:911.

14. Webster RC, Kazda G, Hamden US. Cigarette smoking and facelift: Conservative versus wide undermining. Plast Reconstr Surg 1986;77:596.

15. Govrin J, Kogan L, Luger E, Tamir L, Zeilig G, ShafirR. New method for treating hard-to-heal wounds: Clinical experience with charged polystyrene microspheres. Wounds UK 2010;6:52-61. 